\title{
Toy Pianos, Poor Tools: Virtuosity and Imagination in a Limited Context
}

PLEASE NOTE: this is the "author's manuscript" version. The final version appears in Tempo with minor revisions, and includes numerous score examples.

\section{Xenia Pestova}

\section{Abstract}

The toy piano is fast becoming a concert instrument in its own right, with its own (growing) body of repertoire that has moved well beyond John Cage's 1948 classic Suite for Toy Piano. There are dedicated musicians specialising in toy piano performance all over the world, and numerous composers producing new works written specifically for the toy piano. This unusual miniature instrument provides a respite from the traditional implications of the grand piano, breaks the ice with audiences and allows pianists to perform in locations that would otherwise be inaccessible. In this article the author introduces the history and mechanism of the instrument, performance considerations, extended techniques and approaches to working with electronics, recent repertoire and suggestions for performers and composers. Discussion is supplemented with musical examples.

\section{Biography}

Pianist Xenia Pestova's performances and recordings have earned her a reputation as a leading interpreter of uncompromising repertoire of her generation. Pestova's commitment to promoting music by living composers led her to commission dozens of new works and collaborate with major innovators in contemporary music. Her acclaimed recordings of core piano duo works by Cage and Stockhausen are available on four CDs for Naxos Records. Her solo debut of premiere recordings for the Innova label Shadow Piano was described as a 'terrific album of dark, probing music' by the Chicago Reader. She is Assistant Professor and Director of Performance at the University of Nottingham.

\section{Introduction: Tradition, Portability, Theatre}

Toy pianos were popularised by Albert Schoenhut (1848-1912) in the late 19th century. ${ }^{1}$ Born into a family of German toymakers, Schoenhut immigrated to Philadelphia at the age of 17 , subsequently founding his own toy company with a focus on musical instruments. ${ }^{2}$ Schoenhut's major achievement in toy piano design improvement was to replace the fragile glass plates of the earlier instruments with metal in $1872 .{ }^{3}$ Originally marketed at children from well-to-do families, the toy made a surprising transition into a professional sphere during the Twentieth Century, and is currently enjoying unprecedented popularity as a concert instrument with a growing body of repertoire.

Generally, historical and traditional connotations so often associated with the piano appear to be weakened when it comes to the toy piano, allowing more freedom for composers and performers. Composer Karlheinz Essl writes: 'At the beginning of the 3rd millennium, I had a strange encounter with a strange instrument: the toy piano, which at first didn't attract me that much. On the contrary, I didn't properly estimate its restricted sound possibilities and regarded it quite uninteresting and boring $[\ldots]$ after being forced to dedicate myself to this instrument I soon understood that it has

\footnotetext{
${ }^{1}$ Some of the other toy piano brands include Jaymar (taken over by Schoenhut), Michelsonne (discontinued) and Kawai (rare).

${ }^{2}$ http://toypiano.com, accessed 8 February 2017.

${ }^{3}$ Maggie Williams, 'Child's Play', in International Piano (London, March/April 2007). Available at http://www.isabelettenauer.com/en/reactions/childs-play-international-piano, accessed 8 February 2017.
} 
nothing to do with the piano as we know it. When I hit a key on a regular piano, I am not just hearing a note, but also the whole history of this instrument with its repertory from Bach to Boulez [...] This fact always makes it difficult for me to compose for piano as it always reminds me of historical music that I love - and also abhor. This didn't seem to happen to me when I was playing on the toy piano because its sound has nothing to do with a conventional piano. Instead of strings this instrument has metal rods which are hit by hammers, producing sonic qualities that rather remind me of bells or a celesta, Asian Gamelan, or even an African Kalimba. ${ }^{4}$

While toy piano keyboards mimic grown-up pianos and act as a playful introduction to the piano for children who are too young for lessons, these two very different instruments are more distant than one might imagine. Differences of tone and the action mechanism are vast, and will be explored below. Additionally, the toy piano possesses one very important trait lacking in its big cousin: portability. This is in stark contrast to the fixed rigidity of the piano as we know it today, and is in itself attractive and liberating. The pianist, attached to their grand piano by a metaphorical umbilical chord, is able to bypass practical considerations and perform in milieus that include (for example) a tropical rainforest, a natural cave system, a desert landscape, a mountain top, experimental music lofts and other potential public performance environments where there simply isn't a piano, and no practical way to bring one in. Such opportunities are not normally available unless one travels with one's own grand piano, in which case fitting it into a cave is still likely to present issues. From the author's experience, some of these locations are not even able to support the power required to plug in an electronic keyboard, so toy pianos can be ideal.

The 1948 Suite for Toy Piano by John Cage is often programmed as the cornerstone of repertoire for the instrument. Originally written to accompany a dance work by Merce Cunningham and subsequently arranged for orchestra by Lou Harrison, ${ }^{5}$ the five-movement suite uses only nine notes, and is written masterfully for a truly miniature toy instrument with only white keys, working with limitation to find creative solutions. Cage went on to write Music for Amplified Toy Pianos in $1960^{6}$, taking an entirely different approach. In both works, elements of theatre abound. In the Suite Cage goes as far as to indicate wildly contrasting dynamics (which should be taken with some humour), as well as mysterious diamond noteheads indicating silently-held tones. The latter effect is lost due to the fact that there are no dampers, and holding keys down makes no difference to the resonance; although arguably the notation may influence the physical gesture of the player, and thus the visual impact of the performance. Music for Amplified Toy Pianos gives the performers carte blanche regarding the use of sound-producing objects, resulting in an inherently theatrical visual and aural experience.

By its very nature, the toy piano requires a visually unconventional approach through demanding that the performer either sits on a miniature bench, or places themselves on a cushion in order to play (whichever option may prove to be less awkward in a given situation, based on the performer's physique). The act of crouching on the floor in front of the audience is in stark contrast to the majestic silhouette we associate with the open wing of the concert grand, and acts as an invitation to participate in the event, drawing audiences closer. Traditional barriers between performer and audience are removed, the performer is reduced in stature and can't help contributing to an unusual situation. Humorous and quirky titles in recent compositions seem to reaffirm this ${ }^{7}$.

\footnotetext{
${ }^{4}$ http://essl.at/bibliogr/toypiano-KHE.html, accessed 8 February 2017.

${ }^{5} \mathrm{http}: / /$ johncage.org/pp/John-Cage-Work-Detail.cfm?work_ID=196, accessed 15 February 2017.

${ }^{6}$ The author's performance is available at https://www.youtube.com/watch? $v=3 x Y r G Q 1$ wiWI, accessed 8 February 2017.

${ }^{7}$ For example, pieces such as Snug as a Bug in a Rug from Toy With Me for two toy pianos by David Smooke requires the duettists to move very close together to share one toy piano, four hands (http://www.davidsmooke.com/programnotes/toy.html, accessed 19 February 2017).
} 
Composer and toy pianist Phyllis Chen takes humour and theatre further by frying an egg during performance ${ }^{8}$, while composer Alexa Dexa instructs the performer to synchronise with a working microwave in Microwave Background Radiation.

(Insert Figure 1 here)

Figure 1: Alexa Dexa, Microwave Background Radiation (available from the composer, 2013), used with permission.

\section{The Action}

The mechanism of toy piano action is very different from the "grown-up" grand piano. One of the most common mistakes made by composers and performers approaching this instrument for the first time is the assumption that it is in fact a piano, built on a smaller scale. This is simply not the case, and it may be psychologically and pedagogically easier to treat the toy piano as a completely different instrument with its own set of challenges, requiring an entirely different set of skills and technical considerations for performance.

It is of paramount importance to make peace with the understanding that the toy piano is indeed a toy prior to working with the instrument. Originally designed for the nursery rather than concert performance, the toy piano is not equipped with a vast range of nuance or refinement that we associate with the regular grand piano. If anything, awareness of the simplicity of design can save frustration and disappointment for the aspiring toy piano virtuoso.

Instead of strings, plastic hammers strike metal rods (akin to a big thumb piano), making a characteristic percussive sound and leaving the performer literally no control over the resulting resonance through the plywood body due to the afore-mentioned lack of dampers, or pedals. The tones continue to resonate for several seconds, depending on the acoustics, the model, the individual instrument and how hard the rods were struck. This prolonged and unreliable resonance calls for a rather special and unpianistic articulation: the techniques of playing legato or staccato are not the same as on the regular piano due to this rich resonance. For example, the traditional concept of occasionally employing slight finger overlap to create legato on the piano is not valid in this context. If anything, deliberate non-legato playing can be much more successful in order to achieve clarity of articulation, even if legato is marked by the composer, depending on the dynamic level and model used. Louder dynamic markings can almost transform the concept of legato into a purely psychological rather than physiological experience for the performer.

Awareness and knowledge of this method of tone production calls for a different physical approach to striking the keys. The simple lever mechanism does not allow for fast repetition or subtle control of dynamics: there is nothing in the toy piano approximating the complex double escapement mechanism of the modern grand piano. One has to make special allowances for letting the sound 'breathe', and allowing the instrument to speak instead of forcing pianistic approaches. For example, repeating too fast on the same rod can choke the resonance, actually dampening the sound through hammer contact instead of prolonging it.

However, flourishes, trills and fluid rhythmic structures can work extremely well when not overwhelming the instrument. Sonata for Toy Piano by Michael Finnissy is an excellent example:

(Insert Figure 2 here)

Figure 2, Michael Finnissy, Sonata for Toy Piano (Karlsruhe: Tre Media Verlag, 2006-07), used with permission.

\footnotetext{
${ }^{8}$ https://www.youtube.com/watch?v=e-pfDHzWfts, accessed 8 February 2017.
} 
Needless to say, the range of the toy piano is much smaller than that of most other keyboard instruments. This in itself causes much confusion for composers and performers. The most commonly used commercial model at the time of writing is the 37-key Schoenhut 372 or 379 (the latter with an opening lid), spanning exactly three octaves from $\mathrm{F}$ below middle $\mathrm{C}$ and pioneered by performers such as Phyllis Chen, Isabel Ettenauer and Margaret Leng Tan. There are many other models, with pieces written for specific range or tone colour. While in some cases it may be possible to perform works written for a smaller instrument on a 37-key model (pieces by Karlheinz Essl, Monica Pearce and Yfat Soul Zisso written for a Schoenhut 25-key 'Elite Spinet' work perfectly well on the larger models ${ }^{9}$ ), at times composers ask for specific brands and ranges. The now-obsolete Michelsonne is used in certain works by Karlheinz Essl and Carlos Perales). ${ }^{10}$

(Insert Figure 3 here)

Figure 3: Monica Pearce, Damask for 25-key toy piano and tabla (available from the composer, 2016), used with permission. Pearce has a number of toy piano works in her oeuvre and is the cofounder of the Toronto-based Toy Piano Composers collective. ${ }^{11}$

Further confusion can arise from the fact that the sounding range of one of the 30-key Schoenhut models, the 3005 'Fancy Baby Grand', is not included in the 37-key model range. Despite being more restricted, the range reaches lower, to the $\mathrm{C}$ below the lowest $\mathrm{F}$ on the other models.

Wunderkind by Timothy Roy for toy piano and live electronics is written specifically with this model in mind ${ }^{12}$. This means that a separate instrument has to be obtained just for this piece, even if other toy piano pieces are programmed in the same event.

In addition to the restrictions of range, there are the added complications over varying key sizes. While the Schoenhut models tend to have keys that are only very slightly narrower than standard piano keys, they are still shorter and much shallower, necessitating specific hand positioning and fingerings due to the altered keyboard width and response. This in turn affects hand movements and particularly the transferring of the thumb in rapid passagework. Other toy pianos may have even smaller keys, necessitating entirely different fingerings. Unfortunately, there is no universal solution, and it is therefore vitally important for the performer to practice on the instrument they intend to use in concert to avoid unpleasant surprises.

The range of dynamic contrast varies greatly for each individual instrument, and is generally extremely limited as well, in particular within the softer side of the spectrum. 'Grand' toy piano models tend to be easier to play in comparison to the upright spinets due to the law of gravity, which helps by letting the hammers fall down quicker after playing the keys, increasing the rate of repetition and dynamic control.

The tuning is unstable, varying greatly from instrument to instrument, and very rich in enharmonic content. At times, unpredictable false 'sub-harmonics' can result from the vibration of the wooden frame. Musicians with perfect pitch can find these effects particularly taxing, as higher partials can be stronger than fundamentals on some of the rods, with surprising lower resonances triggered randomly. While tuning the instrument is theoretically not impossible, it would involve filing or

\footnotetext{
${ }^{9}$ Karlheinz Essl, Sequitur V (available from the composer, 2008); Monica Pearce, Damask (available from the composer, 2016); Yfat Soul Zisso, Recollection, (available from the composer, 2016).

${ }^{10}$ Karlheinz Essl, Pachinko, 2013, and Miles to Go, 2012 (available from the composer); Carlos D. Perales, Baby Squirrel (Barcelona: Brotons \& Mercadal, 2014).

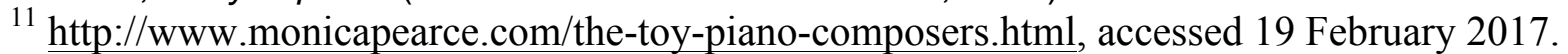

12 Timothy Roy, Wunderkind, (available from the composer, 2012).
} 
soldering the metal rods, and is best abandoned - successful pieces appear to make peace with and embrace the unpredictability.

Composers with no experience of the instrument are often greatly surprised by how their works sound, particularly if very full harmonies are used. Additive resonance of the rods contributes to the general thickness of texture, and the most successful repertoire tends to work with rather than against these limitations, avoiding thick textures and heavy, dense harmonies. Due to the rich specta, chordal writing creates a rather percussive effect, and thinner textures tend to be more transparent and elegant. In this recent work written for the author, Egidija Medekšaite weaves intricate metric counterpoint from relatively simple motifs layered between the two hands, allowing relative freedom of movement for the performer between fragments:

(Insert Figure 4 here)

Figure 4: Egidija Medekšaitè, Chaandanee (EGME editions, 2017), used with permission.

In the following example by Ed Bennett written for the author, notes are added gradually to help propel a crescendo that descends through the full range of the instrument (while rhythmic complexity and formal shaping are created out of repeated rhythmic cells within a single line for the rest of the piece): $:^{13}$

(Insert Figure 5 here)

Figure 5: Ed Bennett, Crazy Legs (Composers' Edition, 2013), used with permission.

\section{Transcending Limitations}

Writing music for a very limited solo instrument such as the toy piano presents a real challenge for the composer. The results are exposed, with little timbral and textural variety to sustain colour and variety. However, working with limitations can also spur creativity and encourage the search for daring and imaginative solutions. Stravinsky famously wrote: 'My freedom will be so much the greater and more meaningful the more narrowly I limit my field of action and the more I surround myself with obstacles. ${ }^{, 14}$ Composers working with the toy piano tend to produce highly unusual repertoire and perhaps consider possibilities that would not otherwise be explored.

Composer and performer David Smooke offers a succinct statement: 'For me, the biggest draw of the toy piano is paradoxically found within its limitations. I enjoy the creative problem solving needed in order to match the tone and musicality of other instruments, and I believe that it's an excellent exercise towards creating new compositions. The same process that has forced me to rethink the possible performance techniques for this toy instrument can be applied to the piano itself or to any instrument for which I'm composing, and that has allowed me to re-consider my basic approach to sound itself. ${ }^{, 15}$

\footnotetext{
${ }^{13}$ While it is impossible to list the full range of available repertoire, other imaginative recent solo pieces for toy piano to explore from the author's repertoire include works by Sean Clancy, Alvin Curran, Christopher Fox, Andrew Lewis, Clio Montrey, Lauren Redhead, Howard Skempton, Ken Ueno, Errollyn Wallen and Michael Wolters.

${ }^{14}$ Igor Stravinsky, Poetics of Music (Harvard: Harvard University Press, 1970), p. 36.

${ }^{15}$ David Smooke, 'Extended Toy Piano', in New Music Box (15 November 2011), available from http://www.newmusicbox.org/articles/extended-toy-piano/, accessed 27 February 2017).
} 
One way to extend the limited capabilities of the toy piano is available through introducing vocal elements and asking the performer to narrate or sing while playing. This approach also builds on the invitation to theatre. Works by Joe Culter and Andrew Hamilton provide fascinating examples ${ }^{16}$.

Some extended techniques are also possible. The rods can be accessed on some models, such as the older versions of Schoenhut model 379, and plucked or struck with percussive objects. Unfortunately, this is not possible on the most recent version of the model 379 . The rods are covered, apparently for child safety reasons. Preparation is an option, with approaches that include placing binder clips on the rods to mute them, a technique pioneered by composer Monica Pearce ${ }^{17}$. In some cases, preparation may require fairly major modifications such as unscrewing and reversing the entire action ${ }^{18}$. Bowing the rods can produce sustained tones, although this requires unimpeded access to the interior of the instrument ${ }^{19}$.

Another interesting technique that can easily be utilised with great success is the loud key click, a constant by-product 'artefact' of the action, as can be seen in this miniature written for the author by Johnny Chang:

\section{(Insert Figure 6 here)}

Figure 6: Johnny Chang, $X X X$ (available from the composer, 2009), used with permission. The composer's instructions state: 'Diamond-shaped noteheads denote half-depressed keys. At no time are actual pitches produced intentionally by the performer.'

Some of the upright spinets can also produce an unintentional but charming 'bebung' bounce when the hammers re-attack the rods, creating a subtle buzz imaginatively explored by composer Patricia Alessandrini in Schattengewächse (2013-14), a guided improvisation for modified toy piano with transducer speakers and live electronics developed in collaboration with the author ${ }^{20}$. The difficulty with this effect is the extreme lack of control and predictability for the performer, as well as the requirement of an upright toy piano model ${ }^{21}$.

The use of electronics, whether live or fixed, offers an additional opportunity to expand and extend the timbral possibilities of the instrument. One of the most frequently performed works for toy piano and fixed media arguably contributed to the toy piano revival of the '00s, a period which witnessed a rapid proliferation of new repertoire. Kalimba by Karlheinz Essl was written in 2005 at the request of pianist Isabel Ettenauer, who is a specialist toy piano performer. The toy pianist is required to place a portable loudspeaker inside the instrument and trigger a soundtrack from an MP3 player. The live performance is then synchronised with pre-recorded sounds, blending the two sound sources and creating complex aural illusions through remarkably simple means, resulting in a portable and elegant 'lo-fi' solution.

${ }^{16}$ Joe Cutler, La maison de Fred (Contemporary Voices, BMIC, 2001) and Andrew Hamilton, More (available from the composer, 2015).

${ }^{17}$ Email correspondence with the author, 19 February 2017.

${ }^{18}$ For example, see Karlheinz Essl, Miles to Go (available from the composer, 2012).

${ }^{19}$ David Smooke, 'Extended Toy Piano', in New Music Box (15 November 2011), available from http://www.newmusicbox.org/articles/extended-toy-piano/, accessed 27 February 2017).

${ }^{20}$ Xenia Pestova, 'Approaches to Notation in Music for Piano and Live Electronics: the Performer's Perspective', in Sallis, Bertolani, Burle, Zattra (eds.), Live-Electronic Music: Composition, Performance and Study (New York and London: Routledge, 2017), forthcoming.

${ }^{21}$ Patricia Alessandrini and Xenia Pestova, 'Creating Music for Bodies, Instruments, and Objects: Live-Generated Scoring for Inclusive Interactive Performance.' Presented at Notation in Contemporary Music: Composition, Performance, Improvisation, Goldsmiths College, University of London, 2014. 
The composer writes: 'The primary aim of this piece is an attempt to break up the restricted sound world of the toy piano - not by superficial means of additional sound processing, but by the sound of the instrument itself. This is achieved by a pre-composed soundtrack, which is played back by a small loudspeaker [...] hidden inside the toy piano. This creates a perfect blend between the sounds of the instrument and the sounds from the loudspeaker. Furthermore, as the listeners won't notice any electronic devices, they might assume that all the music comes from the toy piano itself [...] The result is stunning: starting from the original scale (which is also played synchronously on the toy piano), the sound gradually transforms itself from a rich variety of sonic transformations into a "chaotic" distribution of the 8 tones, which finally fall together into chord repetitions. ${ }^{, 22}$

Essl went on to compose eight more works for toy piano to date, including three with live electronics. Sequitur V, written in 2008, builds up a complex algorithmic canon out of textures played on the instrument, which are recorded and played back by a custom-designed standalone software package. Isabel Ettenauer writes: 'Being confronted with her/his own playing in all sorts of mutations, the performer often feels like in a House of Mirrors. ${ }^{, 23}$ Essl concludes: 'Although the toy piano is tiny in every respect, the sound that it produces in Sequitur $V$ becomes incredibly rich thanks to amplification and real-time sound processing. ${ }^{24}$

Another interesting perspective on writing for toy piano and electronics is found in the work of Carlos D. Perales. Perales is firmly grounded in the classic tradition of solo instrument plus fixed media. However, he takes a highly original approach, identifying a practical solution to the perpetual problem of performer synchronisation with a soundtrack. In Three Liturgies for Schoenhut 37-key model and Baby Squirrel for a smaller Michelsonne one-octave instrument, the performer follows a scrolling score on an iPad, which is synchronised with the audio being sent through the output jack to the loudspeakers. This simultaneously eliminates problems of page turns and click track setup.

James Joslin takes toy piano and live electronics into a semi-improvised environment in his work Coupes la Parole. The performer follows instructions and interacts with a Max/MSP patch in a mobile form environment with the order of the movements different in every performance. Further examples of novel semi-improvised approaches can be found in Patience by Lauren Sarah Hayes. The performer charts their way through a flexible structure where durations depend on resonance and subsequent choices. A Little Bits synth kit is required ${ }^{25}$, adding to the theatricality of performance and DIY aesthetic with switches and dials mounted on Lego-like blocks manipulated by the performer, which control aspects of the electronic soundscape such as the envelope and filtering of the accompanying soundtrack emanating from a portable speaker. ${ }^{26}$

In chamber music contexts, recent works for toy piano seek to expand the limited timbral possibilities through introducing multiple toy pianos as well as combinations with other instruments. qsqsqsqsqqqqqqqqq by Tristan Perich for three toy pianos and three-channel 1-bit tones is an exciting and inventive work that stretches the boundaries of timbre with synchronised canon layering techniques ${ }^{27}$.

\footnotetext{
${ }^{22}$ http://essl.at/works/kalimba.html\#analysis, accessed 18 February 2017.

${ }^{23} \mathrm{http} / / / \mathrm{essl} . \mathrm{at} / \mathrm{bibliogr/ettenauer.html}$, accessed 19 February 2017.

${ }^{24}$ http://essl.at/bibliogr/toypiano-KHE.html\#seq, accessed 8 February 2017.

${ }^{25} \mathrm{http}: / /$ littlebits.cc, accessed 15 February 2017.

${ }^{26}$ Other notable pieces for toy piano and electronics include works by Derek Hurst and Lou Bunk recorded by the author on Shadow Piano (Innova Recordings, INNOVA874, 2014).

${ }^{27} \mathrm{http}$ ://www.tristanperich.com/\#Composition/qsqsqsqsqqqqqqqqq, accessed 19 February 2017.
} 
In other recent chamber music combinations, composer Dai Fujikura introduces toy piano to the violin, Yu Oda and alcides lanza explore the connections and relationships with the standard concert grand piano, while Monica Pearce and Tina Pearson blend different cultural influences in works for toy piano and tabla (see Figure 3). Works by composers Joe Cutler, Karlheinz Essl, Lydia Martin and Errollyn Wallen amongst others combine toy piano and harpsichord. We can also find increasingly numerous successful examples of recent uses of the toy piano in ensemble and orchestral contexts. ${ }^{28}$

\section{Tradition and Innovation}

At the time of writing, eight eager and excited emerging composers are working on new pieces for toy piano following a specialist workshop prior to submitting finalised versions for a performance by the author, while four others are putting finishing touches on their completed toy piano pieces for two other upcoming concerts. While this little instrument does not come anywhere near the grandeur and reliability of the concert grand piano, there is an undeniable and contagious sense of fun as well as sheer joy and silliness that go in tandem with playing one.

The highly successful World Toy Piano Summit at the Philharmonie Luxembourg in 2012 brought together dozens of composers, performers and hundreds of curious audience members of all ages in one unforgettable day, while the first World Toy Piano Day celebration will have launched on 18 March 2017 with online content-sharing and events around the world.

However, not everyone shares this enthusiasm: at least one esteemed pianist colleague confessed to find the very idea of the toy piano 'ridiculous' during an email exchange with the author. In all fairness, given that the toy piano is the instrument of choice of the likes of Beanie the Chicken ${ }^{29}$, it can indeed be a leap of the imagination to ask a virtuoso pianist to perform on a miniature toy after spending decades honing their craft.

Arguably, familiarity with extended techniques and new technologies is increasingly becoming the norm for a performing professional today. While less common, proficiency on a number of keyboard instruments for a pianist is a natural next step, and can be extremely helpful in establishing a versatile career. Playing the toy piano can also provide a much-needed opportunity for pianists to refresh themselves and temporarily walk away from the cultural baggage of the Nineteenth Century, while picking up technical pointers along the way.

David Smooke writes: 'I also like that there really isn't a traditional performance practice for the toy piano. If I get onstage with a piano, there's [sic] hundreds of years of comparison that people just automatically will draw upon. If I choose to play inside the piano and do all sorts of weird things, people will immediately think of John Cage or George Crumb, and if I'm just playing on the keyboard, people will think of Chopin or Beethoven or other composers. With the toy piano the associations are much more personal and much less attached to a cultural tradition. ${ }^{30}$

Although the toy piano might be seen as an opportunity to break away from tradition, it also carries its own associations. According to a recent programme dedicated to toy instruments on BBC Radio

\footnotetext{
${ }^{28}$ Examples include the music of Canadian composer Chris Paul Harman, who frequently employs the toy piano in ensemble and orchestral contexts; specialist ensembles using toy instruments such as Male Instrumenty in Poland founded by Pawel Romanczuk; concerti for toy piano by Matthew McConnell and David Smoke.

${ }^{29}$ https://www.youtube.com/watch?v=05jEcOvzZys, accessed 8 February 2017.

${ }^{30}$ Bret McCabe, 'Peabody's Smooke Debuts Toy Piano Concerto Inspired by Dollhouses, Murder', in $H u b$ (23 April 2014, available from http://hub.jhu.edu/2014/04/23/smooke-nutshell-peabody/, accessed 19 February 2017).
} 
4, many of us naturally appear to associate the bell-like sound of the toy piano with the slightly unnatural world of childhood, creepy lullabies and horror films. ${ }^{31}$ Soberado by Ailís Ní Ríain written for the author explores the darker side of the little instrument by playing with these expectations in a questioning, meandering dialogue that leads to an obsessive and stuttering finale:

(Insert Figure 7 here)

Figure 7: Ailís Ní Ríain, Soberado (available from the composer, 2017), used with permission.

\section{Implications for Pianists}

Despite an abundance of exciting repertoire and possibilities, it can be extremely challenging to make a limited instrument such as a toy piano sound interesting for a substantial period of time. While according to 'the queen of the toy piano,32 Margaret Leng Tan one should be able to achieve anything on the toy piano that one can do on a normal piano ${ }^{33}$, ultimately, there is no contest: the concert grand piano with its marvellous possibilities of colour and tone production wins every time. Or does it?

Imagination and sound quality are of paramount importance to any performer. Setting limitations can be an interesting and useful exercise for pianists as well as composers. In a limited context of transferrable skills on a limited instrument, perhaps these aspects of music making are not so far removed from the challenges of sound production and technique that pianists face in general.

Pianist and scholar Paul Roberts writes: 'The most fundamental [technical problems] relate to the production and control of sound. But sound I believe to be intimately related to imagination [...] Fundamentally, technique is no more than the ability to say what one wants to say: the greatest performing artists are often the greatest technicians because their technique has grown to accommodate their art, not the other way round [...] Performers need to have their imaginations awakened and stimulated before they can make music from the kaleidoscope of sounds the fingers can produce on the keyboard. ${ }^{34}$

While Roberts refers specifically to performing Debussy on the piano, we can expand on this concept of keyboard virtuosity and apply it to learning to control sound and texture in limited contexts and on different instruments. There is something extremely satisfying for a performer about solving a technical puzzle on an instrument that is not even strictly speaking a 'proper' instrument. Can we still make different shadings and gradations of sound within a limited dynamic range? Can we play a particular passage precisely and rhythmically even though the keys do not respond evenly or repeat reliably? Is it possible to discover expression and communication through the medium of plastic hammers and metal rods? Surely, our playing can only benefit from working on making a beautiful sound with limited means.

Margaret Leng Tan concludes: 'When I go back to the real piano [I find that] it's refined my technique no end [...] I can play [...] so reliably now after working with the toy piano. I tell my

\footnotetext{
${ }^{31}$ http://www.bbc.co.uk/programmes/b06sgxjp, accessed 8 February 2017.

32 http://www.margaretlengtan.com, accessed 8 February 2017.

${ }^{33} \mathrm{http}: / /$ archive.jsonline.com/entertainment/arts/112672444.html, accessed 8 February 2017.

${ }^{34}$ Paul Roberts, Images: the Piano Music of Claude Debussy (Portland, Oregon: Amadeus Press, 1996), p. 8.
} 
students: "Take any chance you get to work with a toy piano - it will do so much for your technique." My motto is Marcel Duchamp's statement: "Poor tools require better skills"'. ${ }^{35}$

The pedagogical benefits of working with limitations are familiar to all musicians: as soon as we increase a degree of difficulty, going back to the original material becomes psychologically and physically easier. For example, closing one's eyes and playing in the dark, or adding an octave or two to a difficult leap on the keyboard and mastering this new configuration makes the original version magically possible. Working with a difficult and unresponsive action or in a challenging acoustic environment makes a well-regulated instrument in an accommodating space appear to 'play itself.' Perhaps the ultimate benefit of challenging oneself in the unfamiliar terrain of a limited (but fun) toy keyboard is that by comparison, working with the 'big' piano becomes child's play.

${ }^{35}$ Maggie Williams, 'Child's Play', in International Piano (London, March/April 2007). Available at http://www.isabelettenauer.com/en/reactions/childs-play-international-piano, accessed 8 February 2017. 